\title{
Prescription Opioids and Patient Sex: A National Cross-Sectional Study
}

\author{
Alicia Agnoli, MD, MPH, MHS, Anthony Jerant, MD, and Peter Franks, MD
}

\begin{abstract}
Background: Surveillance data suggest that women are prescribed more opioid analgesics than men. It remains unclear whether these sex-related differences solely reflect the associations with other characteristics more prevalent among women (e.g., adverse socioeconomic and health status-related factors, and more contact with the health system).

Materials and Methods: We examined the factors associated with opioid prescriptions and sex in a large, nationally representative U.S. sample. This observational analysis of the 2005-2015 Medical Expenditure Panel Survey included all adults aged $\geq 18$ years with prescription and health service utilization data $(n=106,233)$. Negative binomial regressions examined associations between sex and number of opioid prescriptions. Analyses sequentially adjusted for sociodemographics, health status-related factors, and nonnarcotic prescriptions. Results: Overall, 9,387 women (16.2\%) and 5,679 men (11.7\%) received opioid prescriptions (female/male incidence rate ratio $[\mathrm{IRR}]=1.35(95 \%$ confidence interval $[\mathrm{CI}]=1.24-1.44)$. The IRR was lower with adjustment for sociodemographics $(1.23[95 \% \mathrm{CI}=1.14-1.31])$ and additional adjustment for health status-related factors $(1.12$ [95\% CI $=1.05-1.19])$. With further adjustment for number of nonnarcotic prescriptions, the IRR was not significant $(0.97[95 \% \mathrm{CI}=0.91-1.03)$.

Conclusions: In this nationally representative sample, women received higher rates of prescription opioids, consistent with prior surveillance data. However, this relationship was attenuated with adjustment for sociodemographic and health status-related factors, and nonsignificant with adjustment for higher rates of nonnarcotic prescriptions among women. Higher opioid prescription rates in women may simply be reflective of these other factors, and the overall greater use of health care among women.
\end{abstract}

Keywords: women, opioids, pain, pain medication, healthcare utilization

\section{Introduction}

$\mathbf{I}^{\mathrm{N}}$ N THE United States, increasing rates of opioid-related morbidity and mortality ${ }^{1,2}$ have heightened concerns related to prescription opioid safety. ${ }^{3,4}$ Although research suggests that such risk is likely consolidated among specific higher-risk populations $2,5,6$ - such as those who misuse prescription opioids, ${ }^{7,8}$ combine them with other centrally depressing medications, ${ }^{9,10}$ or have certain comorbidities ${ }^{4,11,12}$ - our understanding of the risks associated with prescribing opioid analgesics in the general population remains incomplete. ${ }^{13}$ In addition, certain categories of individuals are prescribed opioids at higher rates than others, ${ }^{14}$ suggesting that risk is unevenly distributed within the population. Given growing concerns and increasing scrutiny of clinician management of pain, there is an urgent need to better understand the risks of exposure to prescription opioids.

National data indicate that more women than men are prescribed opioids and that women receive more prescriptions per person. ${ }^{15-17}$ Women also have higher rates of diagnosed painful conditions and depressive disorders, ${ }^{18-20}$ which might complicate both their experience of pain and the treatment of their pain. Because the causal mechanisms for these related phenomena are unclear, exploring how female sex and health conditions are associated with receipt of opioid prescriptions may help develop a more nuanced understanding of opioid prescription use and pain management among women.

In the current study, we examined potential factors associated with higher rates of opioid prescriptions among

Department of Family and Community Medicine, UC Davis School of Medicine, Sacramento, California, USA. 
women. We hypothesized that this sex difference would be associated with three key domains: sociodemographic characteristics, health status-related factors, and higher rates of health care utilization among women. The study analyses assessed the association between sex and receipt of opioid prescriptions in a large, nationally representative U.S. sample, and tested how the associations were affected by adjustment for other patient factors previously associated with opioid prescriptions and/or health status.

\section{Materials and Methods}

\section{Data source}

The Medical Expenditure Panel Survey (MEPS) is a nationally representative survey of health care use and costs in the United States noninstitutionalized population. The survey is conducted annually by the Agency for Health care Research and Quality (AHRQ) as a subset of the National Health Interview Survey and uses an overlapping panel design. Data are collected for each enrollee over two consecutive years through baseline and follow-up interviews. ${ }^{21}$ The MEPS Household Component collects information on interview language, country of origin, sociodemographic information, health insurance coverage, categories of health care utilization, and health care payments. Payments for all categories of health care during the study period are recorded in MEPS through the household survey, and a subsample is verified with data from the physician/pharmacist survey.

We used two additional survey components from MEPS. The Prescribed Medicines file is a subcomponent detailing prescription drug information for all survey participants during each of the follow-up interviews. The Medical Conditions file documents all conditions reported by respondents at each follow-up survey. ${ }^{22}$ We utilized MEPS data from these three components for the years 2005-2015. Response rates declined from $61.3 \%$ to $47.7 \%$ during the study years. ${ }^{23}$

The analytic sample for this study included all adult participants aged 18 or older who provided baseline data and for whom data on prescriptions were available. We used a crosssectional design to assess the associations between sex and other patient factors (sociodemographic characteristics, markers of health status, and health care utilization) and receipt of opioid prescriptions. This study was deemed exempt from review by the University of California Davis Institutional Review Board.

\section{Measures}

The dependent variable in all analyses was number of opioid prescriptions in year 1. Our key independent variable was sex, defined dichotomously as female/male at survey start. We included key variables to account for sociodemographic characteristics, health status-related factors, and health care utilization. In the cluster of sociodemographic covariates, we included age (in years), sex, self-reported race/ethnicity (white, Hispanic, black, other), U.S. census region (Northeast, Midwest, South, West); education level (less than high school, some high school, high school graduate, some college, college graduate); household income level $(<100 \%, 100 \%-124 \%$, $125 \%-199 \%, 200 \%-399 \%$, or $\geq 400 \%$ of the federal poverty level); and health insurance status (uninsured, privately insured, or publicly insured). In the cluster of health status- related variables, we included the 12 -item Short-Form Health Survey (SF-12), Mental Component Summary (MCS-12), and Physical Component Summary (PCS-12) scores. The PCS-12 includes one directly pain-related item, "During the past 4 weeks, how much did pain interfere with your normal work?", Separately, overall self-rated health was assessed by response to the single question "In general, would you say your health is excellent, very good, good, fair, or poor?" Both the SF-12 health status measures and overall self-rated health measure have been shown to independently predict mortality. ${ }^{24,25}$ Additional health-related measures included number of chronic diseases (measured with count of eight self-reported chronic conditions), cancer status (coded if a person reported any visit with a diagnosis of any cancer excluding only nonmelanoma skin cancer), and smoking status (nonsmoker vs. current smoker). As the primary marker of health care utilization not related to opioid management of pain, we included the number of nonopioid prescriptions; separately, we also examined the role of total nonprescription expenditures and the number of physician office visits.

\section{Statistical analyses}

We analyzed data using Stata version 15.1 in 2018-2019. Descriptive analyses, by sex, and by opioid prescriptions, were conducted with $t$-tests and chi-square tests, as appropriate (these analyses did not adjust for survey design). For all regression analyses, we utilized longitudinal strata and primary sampling unit identifiers, with survey weights to account for the complex survey design and sampling design of successive waves of the MEPS. In all models, the key independent variable was patient sex. All analyses adjusted for MEPS panel year to account for potential secular temporal trends.

We performed a sequence of negative binomial regression analyses to assess the association between sex and number of prescription opioids. To test how this association was affected by factors that differ between women and men, we ran a sequence of models that added different clusters of covariates. First, we ran a model adjusting only for sex (and year). The second model added the full array of sociodemographic variables. The third model added adjustment for health status-related factors. The final model included all covariates from the previous models with the addition of the number of nonnarcotic prescriptions as a marker for health care utilization excluding opioid-related pain care. All analyses were complete case analyses.

We conducted supplemental analyses utilizing an alternate measure of health care utilization to examine whether the results in Model 4 were specific to prescription medications or indicative of broader health care utilization effect. For this, we ran the same Model 4, but substituted (1) the logarithm of nonprescription expenditures as the marker for health care utilization instead of nonnarcotic prescriptions and then (2) number of physician office visits.

We examined how much the parameter estimates changed across these models with adjustment for the different categories of variables. We used the Stata command suest to examine the proportional reduction in effect size. ${ }^{26}$

\section{Results}

The analytic sample included 106,233 adult survey participants between the years 2005 and 2015. Women $(n=57,813)$ 
comprised $54.4 \%$ of the sample. Overall, $14.2 \%$ of the sample reported at least one opioid prescription, including $16.2 \%$ of women and $11.7 \%$ of men. Table 1 further summarizes the characteristics of the sample population, comparing those reporting opioid prescriptions received to those reporting none. Adults who received opioid prescriptions were more likely to be older, white, of lower income, live in the Midwest and South census regions, and have public insurance. They were also more likely to have poor health status, with lower average PCS-12 and MCS-12 scores, lower self-rated health, and higher rates of smoking and cancer. Opioid-prescribed adults also had higher rates of nonopioid prescriptions and higher nonprescription healthrelated expenditures.

Table 2 summarizes the sample characteristics by sex (male vs. female). Women in the sample were more likely to be of lower income, have public insurance, and have poorer health status (lower score of both PCS-12 and MCS-12, as

Table 1. Sample Characteristics, by Opioid Prescriptions (Year 1): Any Versus None

\begin{tabular}{|c|c|c|c|c|}
\hline Factor & Total & $\begin{array}{l}\text { No opioid } \\
\text { prescriptions }\end{array}$ & $\begin{array}{c}\text { Any opioid } \\
\text { prescriptions }\end{array}$ & $\mathrm{p}$ \\
\hline$n$ & 106233 & 91167 & 15066 & \\
\hline Age, mean (SD) & $45.7(17.5)$ & $45.3(17.5)$ & $48.7(17.1)$ & $<0.0$ \\
\hline Sex, female & $57813(54.4 \%)$ & $48426(53.1 \%)$ & $9387(62.3 \%)$ & $<0.001$ \\
\hline \multicolumn{5}{|l|}{ Race/ethnicity category } \\
\hline White (non-Hispanic) & $50285(47.3 \%)$ & $41643(45.7 \%)$ & $8642(57.4 \%)$ & \multirow{4}{*}{$<0.001$} \\
\hline Hispanic & $26925(25.3 \%)$ & $24483(26.9 \%)$ & $2442(16.2 \%)$ & \\
\hline Black (non-Hispanic) & $19673(18.5 \%)$ & $16529(18.1 \%)$ & $3144(20.9 \%)$ & \\
\hline Other & $9350(8.8 \%)$ & $8512(9.3 \%)$ & $838(5.6 \%)$ & \\
\hline \multicolumn{5}{|l|}{ Education } \\
\hline$<$ High school & $9344(8.8 \%)$ & $8255(9.1 \%)$ & $1089(7.2 \%)$ & \multirow[t]{5}{*}{$<0.001$} \\
\hline Some high school & $14032(13.2 \%)$ & $11750(12.9 \%)$ & $2282(15.1 \%)$ & \\
\hline HS graduate & $32926(31.0 \%)$ & $27969(30.7 \%)$ & $4957(32.9 \%)$ & \\
\hline Some college & $25542(24.0 \%)$ & $21552(23.6 \%)$ & $3990(26.5 \%)$ & \\
\hline College graduate & $24389(23.0 \%)$ & $21641(23.7 \%)$ & $2748(18.2 \%)$ & \\
\hline \multicolumn{5}{|l|}{ Household income, $\%$ federal poverty level } \\
\hline$<100$ & $19101(18.0 \%)$ & $15691(17.2 \%)$ & $3410(22.6 \%)$ & \multirow[t]{5}{*}{$<0.001$} \\
\hline 100 to $<125$ & $6392(6.0 \%)$ & $5378(5.9 \%)$ & $1014(6.7 \%)$ & \\
\hline 124 to $<200$ & $17474(16.4 \%)$ & $14976(16.4 \%)$ & $2498(16.6 \%)$ & \\
\hline 200 to $<400$ & $31798(29.9 \%)$ & $27562(30.2 \%)$ & $4236(28.1 \%)$ & \\
\hline$\geq 400$ & $31468(29.6 \%)$ & $27560(30.2 \%)$ & $3908(25.9 \%)$ & \\
\hline \multicolumn{5}{|l|}{ Census region } \\
\hline Northeast & $16463(15.5 \%)$ & $14590(16.0 \%)$ & $1873(12.4 \%)$ & \multirow[t]{4}{*}{$<0.001$} \\
\hline Midwest & $21113(19.9 \%)$ & $17637(19.3 \%)$ & $3476(23.1 \%)$ & \\
\hline South & $40440(38.1 \%)$ & $34279(37.6 \%)$ & $6161(40.9 \%)$ & \\
\hline West & $28217(26.6 \%)$ & $24661(27.1 \%)$ & $3556(23.6 \%)$ & \\
\hline \multicolumn{5}{|l|}{ Insurance status } \\
\hline Any private & $62845(59.2 \%)$ & $54219(59.5 \%)$ & $8626(57.3 \%)$ & \multirow{3}{*}{$<0.001$} \\
\hline Only public & $23371(22.0 \%)$ & $18427(20.2 \%)$ & $4944(32.8 \%)$ & \\
\hline None & $20017(18.8 \%)$ & $18521(20.3 \%)$ & $1496(9.9 \%)$ & \\
\hline \multicolumn{5}{|l|}{ SF-12 component, mean (SD) } \\
\hline PCS & $49.1(10.8)$ & $50.3(9.8)$ & $41.6(13.4)$ & \\
\hline MCS & $50.7(10.1)$ & $51.3(9.7)$ & $47.4(11.8)$ & \\
\hline \multicolumn{5}{|l|}{ Self-rated health } \\
\hline Excellent & $24232(22.8 \%)$ & $22445(24.6 \%)$ & $1787(11.9 \%)$ & \multirow[t]{5}{*}{$<0.001$} \\
\hline Very good & $33808(31.8 \%)$ & $30192(33.1 \%)$ & $3616(24.0 \%)$ & \\
\hline Good & $31313(29.5 \%)$ & $26579(29.2 \%)$ & $4734(31.4 \%)$ & \\
\hline Fair & $13032(12.3 \%)$ & $9773(10.7 \%)$ & $3259(21.6 \%)$ & \\
\hline Poor & $3848(3.6 \%)$ & $2178(2.4 \%)$ & $1670(11.1 \%)$ & \\
\hline Count of chronic diseases, mean (SD) & $0.89(1.21)$ & $0.80(1.13)$ & $1.47(1.47)$ & $<0.0$ \\
\hline Any canc & $3683(3.5 \%)$ & $2621(2.9 \%)$ & $1062(7.0 \%)$ & $<0.0$ \\
\hline Current smoker & $19173(18.0 \%)$ & $15222(16.7 \%)$ & $3951(26.2 \%)$ & $<0.0$ \\
\hline res [log], mean (SD) & $5.5(3.2)$ & $5.1(3.2)$ & $8.0(1.8)$ & $<0.0$ \\
\hline Physician office visits in year 1 , mean (SD) & $3.4(6.1)$ & $2.7(5.2)$ & $7.3(9.2)$ & $<0.0$ \\
\hline Opioid prescriptions in year 1 , mean (SD) & $0.5(2.4)$ & $0.0(0.0)$ & $3.7(5.3)$ & $<0.001$ \\
\hline Nonopioid prescriptions in year 1 , mean (SD) & $12.3(22.3)$ & $10.2(19.3)$ & $24.6(32.9)$ & $<0.001$ \\
\hline
\end{tabular}

Data have not been adjusted for survey characteristics. $p$-Values are based on the sample and are not survey-adjusted. The $p$-values indicate $t$-tests or chi-square tests, as appropriate.

MCS, Mental Component Score of the 12-item short-form health survey; PCS, Physical Component Score of the 12-item short-form health survey; SD, standard deviation; SF-12, 12-item Short-Form Health Survey. 
Table 2. Sample Characteristics by SeX

\begin{tabular}{|c|c|c|c|}
\hline Factor & Male & Female & $\mathrm{p}$ \\
\hline$n(\%)$ & $48420(45.6 \%)$ & $57813(54.4 \%)$ & \\
\hline Age, mean (SD) & $45.3(17.3)$ & $46.2(17.6)$ & $<0.001$ \\
\hline \multicolumn{4}{|l|}{ Race/ethnicity category } \\
\hline Non-Hispanic white & $23665(48.9 \%)$ & $26620(46.0 \%)$ & \multirow[t]{4}{*}{$<0.001$} \\
\hline Hispanic & $12430(25.7 \%)$ & $14495(25.1 \%)$ & \\
\hline Non-Hispanic black & $7988(16.5 \%)$ & $11685(20.2 \%)$ & \\
\hline Other & $4337(9.0 \%)$ & $5013(8.7 \%)$ & \\
\hline \multicolumn{4}{|l|}{ Education } \\
\hline$<$ High school & $4347(9.0 \%)$ & $4997(8.6 \%)$ & \multirow[t]{5}{*}{$<0.001$} \\
\hline Some high school & $6465(13.4 \%)$ & $7567(13.1 \%)$ & \\
\hline HS graduate & $15275(31.5 \%)$ & $17651(30.5 \%)$ & \\
\hline Some college & $10900(22.5 \%)$ & $14642(25.3 \%)$ & \\
\hline College graduate & $11433(23.6 \%)$ & $12956(22.4 \%)$ & \\
\hline \multicolumn{4}{|l|}{ Household income, \% federal poverty level } \\
\hline$<100$ & $7051(14.6 \%)$ & $12050(20.8 \%)$ & \multirow[t]{5}{*}{$<0.001$} \\
\hline 100 to $<125$ & $2639(5.5 \%)$ & $3753(6.5 \%)$ & \\
\hline 125 to $<200$ & $7743(16.0 \%)$ & $9731(16.8 \%)$ & \\
\hline 200 to $<400$ & $15184(31.4 \%)$ & $16614(28.7 \%)$ & \\
\hline$\geq 400+$ & $15803(32.6 \%)$ & $15665(27.1 \%)$ & \\
\hline \multicolumn{4}{|l|}{ Census region } \\
\hline Northeast & $7372(15.2 \%)$ & $9091(15.7 \%)$ & \multirow[t]{4}{*}{$<0.001$} \\
\hline Midwest & $9720(20.1 \%)$ & $11393(19.7 \%)$ & \\
\hline South & $18129(37.4 \%)$ & $22311(38.6 \%)$ & \\
\hline West & $13199(27.3 \%)$ & $15018(26.0 \%)$ & \\
\hline \multicolumn{4}{|l|}{ Insurance status } \\
\hline Any private & $29589(61.1 \%)$ & $33256(57.5 \%)$ & \multirow[t]{3}{*}{$<0.001$} \\
\hline Only public & $8405(17.4 \%)$ & $14966(25.9 \%)$ & \\
\hline None & $10426(21.5 \%)$ & $9591(16.6 \%)$ & \\
\hline \multicolumn{4}{|l|}{ SF-12 component, mean (SD) } \\
\hline PCS & $50.0(10.2)$ & $48.4(11.2)$ & $<0.001$ \\
\hline MCS & $51.8(9.7)$ & $49.8(10.4)$ & $<0.001$ \\
\hline \multicolumn{4}{|l|}{ Self-rated health } \\
\hline Excellent & $12198(25.2 \%)$ & $12034(20.8 \%)$ & \multirow[t]{5}{*}{$<0.001$} \\
\hline Very good & $15509(32.0 \%)$ & $18299(31.7 \%)$ & \\
\hline Good & $13762(28.4 \%)$ & $17551(30.4 \%)$ & \\
\hline Fair & $5360(11.1 \%)$ & $7672(13.3 \%)$ & \\
\hline Poor & $1591(3.3 \%)$ & $2257(3.9 \%)$ & \\
\hline Count of chronic diseases, mean (SD) & $0.84(1.19)$ & $0.93(1.22)$ & $<0.001$ \\
\hline Any cancer diagnosis & $1561(3.2 \%)$ & $2122(3.7 \%)$ & $<0.001$ \\
\hline Current smoker & $10313(21.3 \%)$ & $8860(15.3 \%)$ & $<0.001$ \\
\hline Year 1 nonprescription expenditures $[\log ]$, mean $(\mathrm{SD})$ & $4.9(3.4)$ & $6.0(3.0)$ & $<0.001$ \\
\hline Physician office visits in year 1 , mean (SD) & $2.7(5.9)$ & $4.0(6.2)$ & $<0.001$ \\
\hline Opioid prescriptions in year 1 , mean (SD) & $0.4(2.2)$ & $0.6(2.5)$ & $<0.001$ \\
\hline Nonopioid prescriptions in year 1 , mean (SD) & $10.2(20.3)$ & $14.0(23.8)$ & $<0.001$ \\
\hline
\end{tabular}

Data have not been adjusted for survey characteristics. p-Values are based on the sample and are not survey-adjusted.

The $p$-values indicate $t$-tests or chi-square tests, as appropriate.

well as lower self-rated health and greater number of chronic conditions). They had higher mean number of prescriptions, both for opioids and nonopioid medications, as well as higher mean annual nonprescription expenditures.

Table 3 summarizes the adjusted relationships between sex and number of opioid prescriptions in the sequence of negative binomial regression analyses. Model 1 adjusted only for sex and year and yielded an incidence rate ratio (IRR) of 1.36 (95\% confidence interval [CI] $=1.27-1.45)$. Model 2 added adjustment for all sociodemographic variables and revealed the IRR declined to 1.23 (95\% CI $=1.14$ 1.32). The IRR further attenuated with adjustment for health status-related factors in Model 3 (IRR 1.12 [95\% CI $=1.05-$ 1.19]). In the final model (Model 4), with additional adjustment for nonopioid prescriptions, the IRR was 0.97 (95\% CI $=0.91-1.03)$. Results of this fully adjusted model are shown in Table 4.

The right-hand column of Table 3 details the percent reduction in parameter estimates of the effect size between each of the subsequent models compared with the basic model. Model 2, adding adjustment for sociodemographics, demonstrated a $33.0 \%$ reduction in the effect size of the parameter estimate compared to Model 1. Model 3 (further adjusting for health status-related factors) yielded a $64.5 \%$ reduction, and 
Table 3. Adjusted Incidence Rate Ratios for Opioid Prescriptions Received by Women

\begin{tabular}{lcrr}
\hline Negative binomial regression model & $\begin{array}{c}\text { IRR for female sex and opioid } \\
\text { prescriptions (95\% CI) }\end{array}$ & p & $\begin{array}{c}\text { \% reduction in effect } \\
\text { size (95\% CI) }\end{array}$ \\
\hline Model 1: Sex & $1.35(1.27-1.44)$ & $<0.001$ & - \\
Model 2: + Sociodemographics & $1.23(1.14-1.31)$ & $<0.001$ & $33.0 \%(20.1-45.9)$ \\
Model 3: + Health status-related variables & $1.12(1.05-1.19)$ & $<0.001$ & $63.5 \%(47.6-79.4)$ \\
Model 4: + Nonnarcotic prescriptions & $0.97(0.91-1.03)$ & 0.289 & $110.7 \%(89.5-132.0)$ \\
\hline
\end{tabular}

Model 1: Includes only sex and panel year.

Model 2: Adds adjustment for sex, age, race/ethnicity, U.S. census region, education level, income, and health insurance status.

Model 3: Adds adjustment for SF-12 (PCS and MCS scores), self-rated health, chronic disease count, cancer status, and smoking status. Model 4: Adds adjustment for number of nonnarcotic prescriptions in year 1.

CI, confidence interval; IRR, incidence rate ratio.

Table 4. Adjusted Association Between Patient SEX AND Related Factors AND RECEIPT OF OPIOID PRESCRIPTIONS

\begin{tabular}{|c|c|c|}
\hline & $\begin{array}{l}\text { IRR for opioid } \\
\text { prescriptions } \\
\quad(95 \% \mathrm{CI})\end{array}$ & $\mathrm{p}$ \\
\hline Female sex & $0.97(0.91-1.03)$ & 0.291 \\
\hline Age & $0.98(0.98-0.98)$ & $<0.001$ \\
\hline \multicolumn{3}{|c|}{ Race/ethnicity category (ref. $=$ White, non-Hispanic) } \\
\hline Hispanic (any race) & $0.66(0.55-0.78)$ & $<0.001$ \\
\hline Black (non-Hispanic) & $0.85(0.79-0.92)$ & $<0.001$ \\
\hline Other & $0.59(0.52-0.66)$ & $<0.001$ \\
\hline \multicolumn{3}{|l|}{ Education (ref. $=<$ high school) } \\
\hline Some high school & $1.18(1.01-1.37)$ & 0.03 \\
\hline HS graduate & $1.25(1.06-1.47)$ & 0.009 \\
\hline Some college & $1.19(1.02-1.39)$ & 0.024 \\
\hline College graduate & $0.98(0.83-1.16)$ & 0.836 \\
\hline \multicolumn{3}{|c|}{ Household income, $\%$ federal poverty level $($ ref. $=<100 \%)$} \\
\hline 100 to $<125$ & $0.97(0.83-1.13)$ & 0.686 \\
\hline 125 to $<200$ & $0.98(0.89-1.08)$ & 0.724 \\
\hline 200 to $<400$ & $0.93(0.80-1.07)$ & 0.313 \\
\hline$\geq 400$ & $0.94(0.82-1.07)$ & 0.349 \\
\hline \multicolumn{3}{|l|}{ Census region (ref. $=$ Northeast) } \\
\hline Midwest & $1.16(1.00-1.34)$ & 0.047 \\
\hline Sout & $1.17(1.02-1.34)$ & 0.028 \\
\hline West & $1.32(1.13-1.54)$ & 0.001 \\
\hline \multicolumn{3}{|l|}{ Insurance status (ref. $=$ any private) } \\
\hline Only public & $1.06(0.92-1.23)$ & 0.409 \\
\hline None & $0.71(0.63-0.80)$ & $<0.001$ \\
\hline \multicolumn{3}{|l|}{ SF-12 component } \\
\hline Physical component score & $0.94(0.93-0.94)$ & $<0.001$ \\
\hline Mental component score & $0.98(0.98-0.98)$ & $<0.001$ \\
\hline \multicolumn{3}{|l|}{ Self-rated health (ref. $=$ excellent) } \\
\hline Very good & $1.08(0.99-1.18)$ & 0.077 \\
\hline Good & $1.14(1.02-1.27)$ & 0.024 \\
\hline Fair & $1.04(0.93-1.16)$ & 0.483 \\
\hline Poor & $1.14(0.98-1.33)$ & 0.096 \\
\hline Count of chronic diseases & $1.03(0.99-1.06)$ & 0.12 \\
\hline $\begin{array}{l}\text { Current smoker } \\
\quad \text { (ref. = nonsmoker) }\end{array}$ & $1.82(1.63-2.03)$ & $<0.001$ \\
\hline $\begin{array}{l}\text { Any cancer diagnosis } \\
\quad \text { (ref. }=\text { none })\end{array}$ & $1.30(1.17-1.45)$ & $<0.001$ \\
\hline Nonnarcotic prescriptions [log] & $1.61(1.56-1.67)$ & $<0.001$ \\
\hline
\end{tabular}

Model also adjusted for panel year. the final Model 4 (further adjusting for nonopioid prescriptions) revealed a $110.7 \%$ reduction in the effect size.

In the supplemental analyses, a model adjusting for the logarithm of nonprescription expenditures (instead of nonopioid prescriptions) resulted in a sex IRR of $0.92(95 \%$ $\mathrm{CI}=0.87-0.98$ ). The model substituting number of physician office visits resulted in a sex IRR of $1.03(95 \%$ $\mathrm{CI}=0.97-1.09)$.

\section{Discussion}

This study examined rates of opioid prescriptions in a large national survey and analyzed factors associated with disparate rates seen between men and women. The results showed that women received more opioid prescriptions compared with men, consistent with prior surveillance data. The sex difference was progressively attenuated by adjustment for sociodemographics, health status-related factors, and utilization. After finally adjusting for their higher rates of nonopioid prescriptions, women had rates of opioid prescriptions not significantly different from men. This attenuation suggests that the findings of women receiving higher rates of opioid prescriptions are related to their general tendency to have more adverse socioeconomic status and more general adverse health status-related factors, and a general propensity to receive more health care overall. Conversely, the findings do not suggest something additionally specific in the treatment of pain in women.

Our data show women received significantly higher rates of both opioid and nonopioid prescriptions, had higher nonopioid health care expenditures, and more physician visits (Table 2). These are all markers of greater care utilization and are consistent with existing literature relating to sex differences in health care. ${ }^{27-30}$ That the sex effect on the rate of opioid prescriptions essentially disappeared after accounting for nonopioid prescriptions (or nonprescription expenditures or physician visits) suggests that sex-related differences in socioeconomics, health status, and general utilization are the primary drivers of sexrelated differences in opioid prescriptions. There appeared to be no evidence of a residual sex-related difference in opioid prescribing.

Accounting for the sources of greater opioid prescription utilization in women does not mean that there is no risk for women. The factors driving greater utilization in women are also markers of general health vulnerability; risks need to be carefully considered on an individualized basis. Many of the factors we see associated with receiving opioid 
prescriptions (poorer health status, tobacco use) are known to increase a patient's risk for an adverse outcome related to these prescriptions.

Our study had limitations. First, we are unable to examine subsequent risks associated with higher rates of opioid prescriptions. Although the study was not designed to examine these risks, we mention this contextual limitation to highlight the broader circumstances in which such findings are interpreted. Second, we did not examine the doses or duration of opioid prescriptions received, but rather the count of opioid prescriptions. As prior studies have suggested that men receive higher doses of opioid prescriptions than women, ${ }^{31}$ sex differences in opioid prescription doses likely represent a related but separate phenomenon that merits analysis. ${ }^{32,33}$ The self-report MEPS does not include dose or duration information. Third, nonresponse rates may have introduced some bias in our findings, as it is unknown how opioid-related health care differed among those who did not complete the survey (especially sex-related differences). Some predictors may be endogenous with the dependent variable (number of opioids). For example, the PCS-12 includes an item on pain, so including the SF-12 may be overadjusting. Notably, however, the MCS-12, which also predicted opioid prescription use (Table 4), does not include a pain-related item. The data extended only through 2015 , the last year that data were available. Finally, this was an observational study that may have unmeasured confounding.

\section{Conclusions}

In this nationally representative sample of U.S. adults, we found that women were not more likely than men to receive opioid prescriptions after adjusting for their higher rates of nonopioid-related health care utilization. The observed attenuation suggests that prior findings from surveillance data have merely reflected general sex-related differences in sociodemographics, health status, and overall health care utilization. While it remains possible that there is something unique about women and the treatment of pain, our analysis found no evidence that this was driving their higher rates of prescription opioids. The findings point to the need for ongoing work to better understand the relationships that may drive increased risk for women and opioid prescriptions.

\section{Author Disclosure Statement}

Drs. A.A., A.J., and P.F. each confirm that no competing financial interests exist.

\section{Funding Information}

Role of the funding source: Dr. Agnoli's work on this project was supported by the Dean's Scholar in Women's Health Research (DSWHR) career development award, funded by the UC Davis School of Medicine Dean's Office. The funding source had no role in the study.

\section{References}

1. Rudd RA, Seth P, David F, Scholl L. Increases in drug and opioid-involved overdose deaths-United States, 2010 2015. MMWR Morb Mortal Wkly Rep 2016;65:1445-1452.
2. Chen LH, Hedegaard H, Warner M. Drug-poisoning deaths involving opioid analgesics: United States, 1999-2011. NCHS Data Brief 2014:166:1-8.

3. Kolodny A, Courtwright DT, Hwang CS, et al. The prescription opioid and heroin crisis: A public health approach to an epidemic of addiction. Annu Rev Public Health 2015; 36:559-574.

4. Quinn PD, Hur K, Chang Z, et al. Incident and long-term opioid therapy among patients with psychiatric conditions and medications: A national study of commercial health care claims. Pain 2017;158:140-148.

5. Dunn KM, Saunders KW, Rutter CM, et al. Opioid prescriptions for chronic pain and overdose: A cohort study. Ann Intern Med 2010;152:85-92.

6. Zhang Y, Johnson P, Jeng PJ, et al. First opioid prescription and subsequent high-risk opioid use: A national study of privately insured and medicare advantage adults. J Gen Intern Med 2018;33:2156-2162.

7. Hemsing N, Greaves L, Poole N, Schmidt R. Misuse of prescription opioid medication among women: A scoping review. Pain Res Manag 2016;2016:1754195.

8. Boscarino JA, Rukstalis M, Hoffman SN, et al. Risk factors for drug dependence among out-patients on opioid therapy in a large US health-care system. Addiction 2010;105: 1776-1782.

9. Carico R, Zhao X, Thorpe CT, et al. Receipt of overlapping opioid and benzodiazepine prescriptions among veterans dually enrolled in medicare part D and the department of veterans affairs: A cross-sectional study. Ann Intern Med 2018;169:593-601.

10. Centers for Disease Control and Prevention (CDC). Vital signs: Overdoses of prescription opioid pain relievers and other drugs among women-United States, 1999-2010. MMWR Morb Mortal Wkly Rep 2013;62:537-542.

11. Reid MC, Engles-Horton LL, Weber MB, Kerns RD, Rogers EL, O'Connor PG. Use of opioid medications for chronic noncancer pain syndromes in primary care. J Gen Intern Med 2002;17:173-179.

12. Corrigan JD, Adams RS. The intersection of lifetime history of traumatic brain injury and the opioid epidemic. Addict Behav 2019;90:143-145.

13. Chou R, Turner JA, Devine EB, et al. The effectiveness and risks of long-term opioid therapy for chronic pain: A systematic review for a National Institutes of Health Pathways to Prevention Workshop. Ann Intern Med 2015; 162:276-286.

14. Breckenridge J, Clark JD. Patient characteristics associated with opioid versus nonsteroidal anti-inflammatory drug management of chronic low back pain. J Pain 2003; 4:344-350.

15. Serdarevic M, Striley CW, Cottler LB. Sex differences in prescription opioid use. Curr Opin Psychiatry 2017;30:238246.

16. Simoni-Wastila L. The use of abusable prescription drugs: The role of gender. J Womens Health Gend Based Med 2000;9:289-297.

17. Back SE, Payne RL, Simpson AN, Brady KT. Gender and prescription opioids: Findings from the National Survey on Drug Use and Health. Addict Behav 2010;35:10011007.

18. Blackwell DL, Lucas JW, Clarke TC. Summary health statistics for U.S. adults: National health interview survey, 2012. Vital Health Stat 10 2014:260:1-161. 
19. Darnall BD, Stacey BR, Chou R. Medical and psychological risks and consequences of long-term opioid therapy in women. Pain Med 2012;13:1181-1211.

20. Fink DS, Hu R, Cerda M, et al. Patterns of major depression and nonmedical use of prescription opioids in the United States. Drug Alcohol Depend 2015;153:258264.

21. Medical Expenditure Panel Survey (MEPS). Agency for Healthcare Research and Quality, Rockville, MD. Available at: www.ahrq.gov/research/data/meps/index.html Accessed June 3, 2019.

22. Medical Expenditure Panel Survey (MEPS). Agency for Healthcare Research and Quality, Rockville, MD. Available at: https://meps.ahrq.gov/mepsweb/survey_ comp/household.jsp. Accessed June 3, 2019.

23. Medical Expenditure Panel Survey (MEPS). Agency for Healthcare Research and Quality, Rockville, MD.. Available at: https://meps.ahrq.gov/survey_comp/hc_response_ rate.jsp. Accessed June 3, 2019.

24. DeSalvo KB, Bloser N, Reynolds K, He J, Muntner P. Mortality prediction with a single general self-rated health question. A meta-analysis. J Gen Intern Med 2006; 21:267-275.

25. DeSalvo KB, Fan VS, McDonell MB, Fihn SD. Predicting mortality and healthcare utilization with a single question. Health Serv Res 2005;40:1234-1246.

26. Clogg CC, Petkova E, Haritou A. Statistical methods for comparing regression coefficients between models. Am J Sociol 1995;100:1261-1293.

27. Franks P, Clancy CM, Naumburg EH. Sex, access, and excess. Ann Intern Med 1995;123:548-550.
28. Verbrugge LM, Steiner RP. Physician treatment of men and women patients: Sex bias or appropriate care? Med Care 1981;19:609-632.

29. Owens GM. Gender differences in health care expenditures, resource utilization, and quality of care. J Manag Care Pharm 2008;14(3 Suppl):2-6.

30. Williams JS, Bishu K, Dismuke CE, Egede LE. Sex differences in healthcare expenditures among adults with diabetes: Evidence from the medical expenditure panel survey, 2002-2011. BMC Health Serv Res 2017;17:259.

31. LeResche L, Saunders K, Dublin S, et al. Sex and age differences in global pain status among patients using opioids long term for chronic noncancer pain. J Womens Health (2002) 2015;24:629-635.

32. Niesters M, Dahan A, Kest B, et al. Do sex differences exist in opioid analgesia? A systematic review and meta-analysis of human experimental and clinical studies. Pain 2010;151: 61-68.

33. Vambheim SM, Flaten MA. A systematic review of sex differences in the placebo and the nocebo effect. J Pain Res 2017;10:1831-1839.

Address correspondence to: Alicia Agnoli, $M D, M P H, M H S$ Department of Family and Community Medicine

UC Davis School of Medicine 4860 Y Street, Suite 2300

Sacramento, CA 95817

USA

E-mail: aagnoli@ucdavis.edu 